\title{
Based On Task Driven Military Case Teaching Practice and Thinking
}

\author{
Lin Zhang and Liang Ma \\ Department of missile, Dalian Naval Academy, Dalian, 116018, China \\ Department of Surface Ship Command, Dalian Naval Academy, Dalian, 116018, China \\ 446982051@qq.commailbox1015@126.com
}

\begin{abstract}
Keywords: Task driven; Task-based learning; Comprehensive practice; Teaching mode
\end{abstract}
\begin{abstract}
Task driven" teaching (Task -based Learning) is a kind of wide attention in recent years by the method of teaching. Task drive, refers to the students to study in close contact, life and social practical meaningful task context, by completing the task to learn the knowledge, skills, forming ability. In the teaching process, teachers teaching content into one or more specific tasks, makes every effort to task drive, and then put forward problems, guide the learners to think about. Both faculty and students are around how to accomplish a specific task to carry out teaching activities. A task by many teaching contents together, this process, students complete the task is not only the process of learning knowledge content, is also the process of integrated use of knowledge.
\end{abstract}

\section{Introduction}

Traditional teaching tend to have fixed teaching content, basic unified teaching procedures, in the form of faculty explanation or lectures to students knowledge, finally with some good structure into the problem of test paper, test whether students master the knowledge. In this kind of teaching mode, teachers and students: the role of teachers to teach and students learn. In TBL teaching process, students are often placed in a complex structure and undesirable situations, and to learn to analyze the problem by themselves, with the knowledge necessary to solve the problem, if necessary through team collaboration, step by step to solve the problem. Faculty tasks and problems in the real life as the teaching material, constantly inspire students to think. This study is to make students learn in the actual problem situation, let they combine knowledge and real life, to cultivate their learning interest and learning initiative, but also let them construct their own knowledge framework.

The real task or problem is an organization of TBL center, and sustain it arouses the students' interest. TBL tasks should be derived from the learners' study and life in the real world, rather than the imagination. Good task context connotation is rich, worth thinking about, and enlightening rich education significance, to effectively combine students' knowledge learning and the actual life. The faculty in the design task, should not only consider the relationship between knowledge and knowledge, discipline and discipline, and students' characteristics and needs, give attention to two or morethings can attract the students to find a job presentation.

\section{Cases based on Task Driven Teaching Characteristics}

The Teaching Material is from the Real Case. Case itself is derived from the real events in a professional field, after the student graduates, may be about to face a similar problem, this on the background of actual case teaching mode can arouse the enthusiasm of students learning, change the boring teaching atmosphere, stimulate students actively case, and put forward problems, analyzing problems according to their own understanding, to solve the problem.

To Students as the Main Body, is Given Priority to with Heuristic, Discussion, Interactive Teaching Methods. Teacher after introduces the case, students will first learned with their theoretical knowledge to active thinking and creativity, to find the reason and the method to solve the problem, and teachers just heuristic to guide the students to think and discuss. Late in case teaching, the students and between students, between students and teachers can also be a discussion 
and communication, forming a warm, interactive, lively teaching atmosphere, make the students can fully express their new ideas and new insights and facilitate the thinking of communicate with each other, inspire each other and complement each other. Obviously, this kind of teaching method is completely different from mainly teachers teach, students passively receiving knowledge of the traditional teaching mode, it emphasizes the full participation of students, can fully mobilize students' enthusiasm, initiative and self-consciousness, improve students thinking ability and practical ability, to cultivate the students' ability of independent analysis to solve the problem, and make teachers and students with good interaction, teaching is learning.

Realize the Close Combination of Theory with Practice. The traditional teaching usually only to tell students what to do, and its content may not be practical in practice, easy to cause the theory and practice, to a certain extent, affected the enthusiasm of students. Case teaching is an actual case class from the actual work in the future, can provide students with practical problems linked to the application of the background, make the students in the concrete practice, attract the students' curiosity, continuously stimulate students seeking knowledge desire, make students take the initiative to combine theoretical knowledge with practical application.

\section{Task Driven Teaching Model}

Different from traditional teaching teaching procedures and teaching model of the single, linear, TBL is a relatively complex process of teaching. It requires that teaching activities should be in a real open or close to the real situation and to avoid the knowledge, and knowledge process simplification, abstraction. Thus the teaching process more flexible.

TBL Model. In TBL, faculty often crafted some tasks and the problem situation, in which students study actively for problem solving, rather than passive acceptance; Faculty members are not let go no matter, but should be timely to give necessary guidance to students, especially in cognitive, metacognitive and give guidance on learning methods and strategies. According to TBL teaching and elements of TBL model can be indicated as follows:

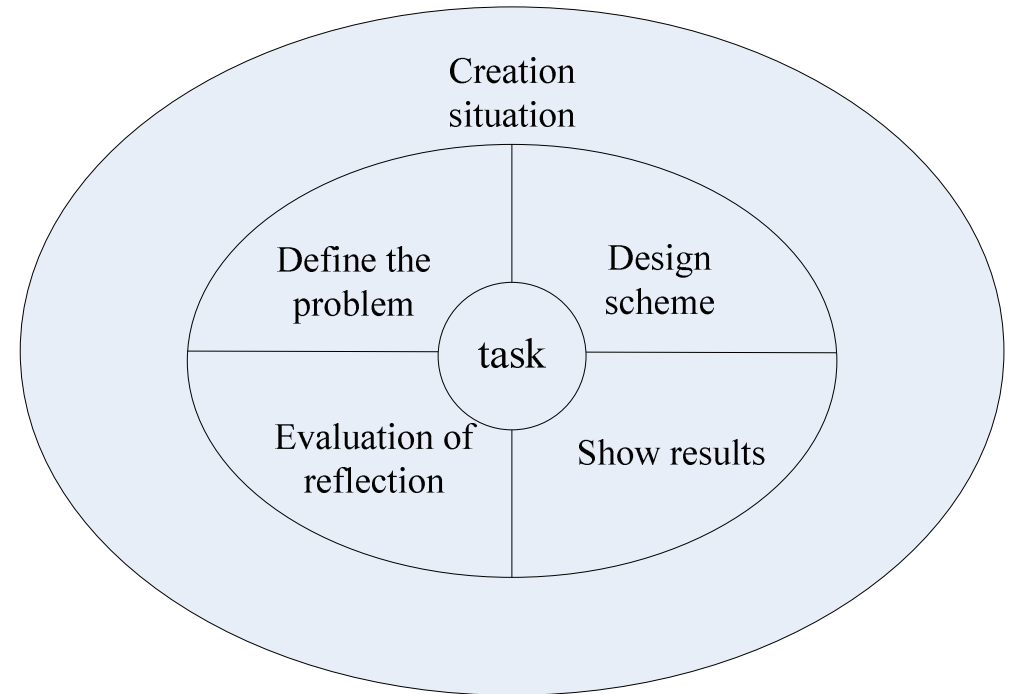

Figure 1. Learning model

As shown in fig. 1 model, TBL put the whole learning process in a certain situation, this kind of situation is derived from the real world or close to the real world situation, is closely related to the learner's life. In this context is presented to learners a task topic, all teaching activities around the task group; Starting from the central task, students and teachers together to analyze problems, according to the actual situation design and implementation of the scheme to solve the problem; Students to all the participants show results, by the faculty and students to evaluate learning effect, cause students reflection to the learning process. In this process, the teaching activities of each link sequence is not rigid cannot be changed, students can adjust the order according to their own 
situation, also can learn the behind some of the links and then repeat the previous step. In the process of task to solve, teachers guide and encourage students, thorough understanding of the problem.

TBL Teaching Link. TBL revolves around a problem, give students sufficient rights in learning, let students play initiative of learning, can also choose to suit their own learning style. Therefore, in the TBL model above, each module can be applied flexibly according to different students. But in general, TBL also has its popular teaching link and process, figure 2-2 describes the process of TBL teaching activity.

\section{The Implementation of the Task Driven Teaching Style}

For faculty and students are accustomed to traditional teaching mode, the implementation of a primary issue is the role of TBL transformation. In TBL, faculty and students are facing a new role.

Here students to become the main body of learning activities, constantly in the process of learning on their own to find and solve problems, construct knowledge; Faculty become positive guidance and participants, like students into learning activities. In the process of implementation of TBL, the mission of the faculty was first diagnosed with the learning needs of students, and provide students with whatever they needed help, and at the right time to insert the appropriate explanation, and even direct teaching. Although TBL teaching emphasis on the subjectivity of the students and enthusiasm, but also does not reject "teaching". Faculty can also by guiding, asking questions, demonstration and so on way to inspire and motivate students to carry on the deeper thinking, but all of these in the teaching activities should grasp a degree problem.

TBL is another point to be highlighted in the implementation of activities faculty to adjust and control. In TBL learning activities, usually require students the collective to complete certain tasks, such as collect and share information, discuss the solution, etc., therefore effective on collective activities to prepare in advance and it is very important in activity management, make each and every team is response for learning activities of rights and responsibility. In TBL activities, teachers often ask students to play the role of a real task, so teachers should help students prepare for the role that the, as well as to guide the students' activities, and when necessary need for certain not to participate in activities of participants to intervene. Faculty members also need to pay attention to problems arising from the activities, such as why some students do not participate in activities? If they are not interested in these? To take corresponding measures in time, to regulate activities.

TBL learning need faculty appropriate inserted in the process of interpretation and evaluation. The main purpose of assessment is to improve teaching and promote learning, in TBL evaluation is a dynamic process, rather than a summary of a independent part. As the ongoing learning process evaluation, faculty, students in the process of learning what you need can be determined, and then through a variety of effective ways to insert the corresponding interpretation, in order to help students to reveal problems related important information. By inserting the evaluation and interpretation, can avoid the deviation from the direction of the task topic, learning process to ensure that TBL smoothly.

\section{Several Measures to Improve the Effect of Military Case Teaching}

To Strengthen the Construction of Teachers Team, Real Close to the Forces. Closely with military training and the actual equipment joint military case involves a lot of new knowledge, new technology and new ideas, which requires teachers in addition to have a deep and solid professional knowledge, familiar with relevant professional fields and development of the frontier; In addition to possess strong observation, analysis, problem solving skills, and familiar with military training practical and typical failure of weapons and equipment, should have more control the classroom, guide the students' ability of analysis problem.

Classroom teachers in addition to strengthen their professional knowledge, vision, ability, and quality of reserve, and optimize their knowledge structure, register in person with the force 
corresponding post office function in an acting capacity, familiar with military training organization procedure, and forces the grassroots leaders of advantage complementary two-way communication, hold the characteristic of troops training work, understand forces the position and development needs, and pay attention to collect typical cases, a targeted writing case, enrich the teaching content to the greatest extent.

The Students to be Familiar with the Case before the Class Content. Different from traditional teaching, case teaching is high to the requirement of students, students one to two weeks before the class is about to get teacher carefully choose good material, let the students to fully familiar with the case, and on the basis of careful analysis of case material, combined with their professional knowledge, experience and related information, ask questions, give their own opinions, achieve knowledge. Only be fully prepared, students will truly into to the case teaching, and actively participate in the case analysis, classroom atmosphere will be heated debate, vivid, inspired teachers guide is targeted, the teaching effect will be more obvious.

The Teacher wants to Guide is Given Priority to with Inspiration. To avoid in the case teaching to the teacher as the center, to pay more attention to the subject status of students in teaching. The fact of the case discussion process, are given in case and students on the basis of the theory of knowledge, experience knowledge, through discussion and interaction between students, inspire each other, complement each other, through the interaction between teachers and students to excavate potential problems in the case, and then puts forward the solutions to solve the problem. During the discussion, the teacher is guide, the main body of students is discussed, but students of the discussion is not aimlessly, but on the basis of personal preparation, under inspired teachers guide, along a predetermined classroom teaching design. Students under the guidance of teachers to actively participate in case preparation, analysis, discussion and summary, change passive learning habit, to form the habit of active learning, active thinking of prisoners. Through this interactive enlightening guidance, students' ability of problem analysis and problem solving method and will greatly improve, but also conducive to the cultivation of the students' ability of divergent thinking and innovation.

The Performance of the Students to Encourage and Sure. Used for real case of case teaching, there is no "standard answer", in the process of case discussion, to encourage students to speak. Teachers to students of all kinds of ideas, and even the one-sided and wrong viewpoints are not ridicule, criticism and negation, carefully listen to the students original ideas for the case, the sparking spots in efforts to find their thinking and innovation, and should be encouraged and timely correct guidance, training students' ability of analysis, judgment and decision, must be good at control process of case discussion, make students have the opportunity to participate in discussions as much as possible, ensure scope don't deviate from the topic.

Encourage students from different positions open up, speak up, because speaking is important source of information, students and teachers only if we respect each other, listening and communication, improve teamwork, to inspire each of the students' active participation motivation, to promote common progress, to achieve the purpose of teaching is learning.

Increase in Military Case Resources Construction Spending. To clear the number of cases in case wants moderate, category, level must clear, want to hold people accountable for putted forward construction, and construction of the good case review, to ensure that the case should not only close to the practice of military training and the typical representative, illuminating and warning, and keep pace with the development of the army training and actual weapons and equipment.

To build a good case to appoint the maintenance and updated dynamically. In order to make the case teaching keep up with the requirements of military training and reflects the current situations of weapons and equipment, and need to keep the freshness and efficiency of the case, need to be putted forward already in the old cases in a timely manner. To force in the construction and training of new problems, if there is no corresponding case in the case, to timely supplement and correction, putted forward a real time, so as to enhance students' interest in learning, improve the teaching effect. 
In case teaching, in order to make students have immersive feeling, should pay attention to case teaching conditions of construction, construction and form a complete set of case teaching venues and facilities. As in the launcher of typical fault detection and ruled out the case teaching, if there is a matching launcher as teaching facilities, fault detection and ruled out to be taught to the launcher, will greatly arouse the enthusiasm of students learning, have the teaching effect of get twice the result with half the effort.

\section{Conclusion}

Set up the student centered training concept is the key to to ensure the quality of personnel training. Case teaching method in improving students' ability quality and solving practical problems in troops has a unique role. But, the military case used in specialized course teaching is still in its infancy, so the military construction and the implementation of case teaching, the case should be combined with the specific situation, step by step, the reasonable effective, only by constantly explore, continue to improve, to play their role in talent training in military schools.

\section{Reference}

[1] Galay Barbarosoglu, Linet Ozdamar, Ahmel Cevik. An Interactive Appmach of Hierarchical Analysis of Helicopter Logistics in Disaster Relief Operations[J]. European Journal of Operational Research, 2002: 118-133

[2]Sriram Venkataramanan, Atilla Dogan. A Multi-UAV Simulation for Formation Reconfiguration[R]. AIAA 2004-4800. Providence, Rhode Island: AIAA Modeling and Simulation Technologies Conference and Exhibit,2003

[3] M. Valenti, T. Schouwenaars, Y. Kuwata, E. Feron and J. How Implementation of a Manned Vehicle-UAV Mission System[C].AAIA Guidance, Navigation and control Conference, Providence, RI, August 2004,AIAA2004

[4] M.Ben-Bassat. Knowledge Requirement and Management in Expert Decision Support Systems for (Military) Situation Assessment[J]. IEEE Trans. on SMC.1982, 12(4):479-490

[5] Jerome Azarewicz, Glenn Fala. Template-based Multi-agent Plan Recognition for Tactical Situation Assessment[A].In: Proceedings of 5th conference on Artificial Intelligence Applications[C], March 1989:247-254

[6] G. Peterson, L. Axelsson, T. Jensen, etal. Multi-source Integration and Temporal Situation Assessment in Air Combat[J]. Proceedings of Information Decision and Control.1999:371-375

[7] Ge S S,Cui Y J. Dynamic motion planning for mobile robots using protential field method[J].Autonomous Robots,2002,13:207-222 